\title{
Predictors of Disease Recurrence Post Living Donor Liver Transplantation in End Stage Chronic HCV Patients
}

\author{
Mostafa K. El Awady, ${ }^{1}$ Noha G. Bader El Din, ${ }^{1}$ Mahmoud Abdel Aziz Riad, ${ }^{2}$ \\ Moataza H. Omran, ${ }^{1}$ Tawfeek H. Abdelhafez, ${ }^{1}$ Tamer Mahmoud Elbaz, ${ }^{3}$ \\ Shereen Shoukry Hunter, ${ }^{3}$ Reham M. Dawood, ${ }^{1}$ and Ashraf O. Abdel Aziz ${ }^{3}$ \\ ${ }^{1}$ Department of Microbial Biotechnology, National Research Center, Dokki, Cairo 12622, Egypt \\ ${ }^{2}$ El Sahel Teaching Hospital, Ministry of Health, Al Kornich Shoubra, Cairo, Egypt \\ ${ }^{3}$ Department of Tropical Medicine, Kasr El Aini, Cairo University, Cairo, Egypt
}

Correspondence should be addressed to Mostafa K. El Awady; mkawady49@yahoo.com and Noha G. Bader El Din; nbadereldin@yahoo.com

Received 11 August 2013; Revised 14 December 2013; Accepted 24 December 2013; Published 18 February 2014

Academic Editor: Luisella Bocchio-Chiavetto

\begin{abstract}
Copyright (C) 2014 Mostafa K. El Awady et al. This is an open access article distributed under the Creative Commons Attribution License, which permits unrestricted use, distribution, and reproduction in any medium, provided the original work is properly cited.

HCV recurrence represents a universal phenomenon after liver transplantation. In this study Fifty HCV patients who underwent living donor liver transplantation were enrolled and factors that may accelerate HCV reinfection of the allograft such as donor's age and degree of liver steatosis, recipient's age, gender, BMI, MELD score, liver functions, HCV viral load, type of immunosuppressive drug, and genetic polymorphisms of IL28B, OAS, and IL1B were studied. The results of disease-free survival (DFS) rates showed inverse correlation with the recipient's postoperative levels of ALT, AST, ALP $(P<0.001,<0.001$, and 0.006 resp. $)$ as well as preand postoperative titers of HCV RNA $(P<0.003$ and $<0.001$ resp.). Recipient's IL28B SNP was a significant factor in predicting postoperative DFS $(P<0.025)$. However, SNPs in OAS and IL1B genes had no apparent correlation with DFS. Cox proportional hazards model revealed that patients with elevated levels of ALT, preoperative viral titers, IL28B CT, and IL28B TT were 8.28, 4.22, 3.35, and 1.36 times, respectively, more likely to develop recurrence. In conclusion IL28B SNP, ALT level, and preoperative HCV titer besides proper choice of immunosuppressant are helpful for predicting posttransplant HCV recurrence and DFS.
\end{abstract}

\section{Introduction}

Chronic HCV infection is a leading cause of end-stage liver disease and hepatocellular carcinoma worldwide. Liver transplantation (LT) is a principal choice for treating patients with advanced liver disease. End stage liver disease associated with hepatitis $\mathrm{C}$ virus infection constitutes one of the principal indications for liver transplant. Unfortunately, reinfection of the graft (HCV recurrence) represents a universal phenomenon after LT and accounts for nearly half of all transplantations [1]. The majority of patients with virological recurrence will develop histological graft injury, chronic infection in $75-90 \%$ of transplant patients, and within 5 years, one-third of patients developing cirrhosis [2-4]. In addition, time interval from HCV cirrhosis to decompensation is significantly shorter in LT recipients than in nontransplant patients. It was reported that $5-30 \%$ of patients lose their graft due to HCV recurrence after liver transplantation $[5,6]$. Also, HCV infection carried a higher risk of death 1 year after transplant as well as high risk of retransplantation. Generally, $\mathrm{HCV}$ recurrence decreased patient and graft survival in the long-term time frame [1].

The Egyptian population has a heavy burden of liver disease, mostly due to chronic infection with hepatitis $\mathrm{C}$ virus $[7,8]$. The end stage liver disease (ESLD) secondary to HCV infection has become an increasing cause of mortality in Egypt in the last decades [9]. A study done by Yosry et al. [10] showed that hepatitis C related ESLD is the main indication for liver transplantation and represents $89.8 \%$ of cases in Egypt, while HBV and other indications (cryptogenic cirrhosis, Wilson disease, and glycogen storage disease) represent 5.1\% and 5.1\% respectively. Across different countries 
and transplantation programs, the 5-year posttransplantation survival rate for hepatitis $\mathrm{C}$ patients is significantly lower as compared to patients who underwent liver transplantation for other chronic liver diseases [11].

In the transplant setting, many factors contribute to disease progression compared with nontransplant patients. Factors associated with accelerated HCV recurrence after LT are related to the host (demographics, genetic background, immune status, sex, coinfections, and hepatic function at transplantation), the virus (genotype, viral replication, and viral quasispecies), and the donor (older age, degree of hepatic steatosis, weight, living versus cadaveric, anti-HCV status, and prolonged ischemic time), the environment (surgery-related factors, immunosuppression, alcohol). The viral and iatrogenic parameters were highly examined in many studies, while little is published on host factors [12]. Interestingly, in the immunocompetent population, the most powerful predictors of disease severity are those related to the host, while virus-related factors do not seem to play a major role in determining outcome. In particular, age at the time of infection, alcohol intake, and gender strongly affect disease progression $[4,13]$.

In addition, several factors have been discussed to influence the long-term outcome of graft such as the degree of human leukocyte antigen (HLA) matching or the IL28B genotype of the donor and the recipient [11]. There is now strong evidence for the important role of heritability in host immune responses to infectious pathogens and for susceptibility and outcome after exposure to microbial agents. Both the major histocompatibility complex (MHC) genes and nonMHC genes are increasingly identified as candidate genes with significant importance in the outcome of infectious diseases [12]. It was reported that any genetic variants that affect OAS1 activity could be important determinants of susceptibility/resistance to antiviral treatment and to virusrelated disease progression [14]. Recently it was demonstrated that IL-28 $\beta$ SNPs play important roles in the management of hepatitis $\mathrm{C}$ virus ( $\mathrm{HCV}$ ) infections and are strongly associated with spontaneous and treatment-induced HCV clearance [11, $15,16]$.

Identifying patients at risk for accelerated allograft loss is very important so that consideration can be taken in a timely fashion to use antiviral agents and/or decision to retransplant. Therefore, there is a great need for biomarkers capable of accurately predicting HCV recurrence after LT and monitor disease progression. In the present study we will examine factors related to donor (age, liver steatosis), pretransplant recipient (age, sex, HCV viral load, coinfections, SNPs of OAS gene, IL1 $\beta$ and IL- $28 \beta$ gene and posttransplant recipient immunosuppressive drugs, i.e., cyclosporine (CS), FK, and mycophenolate mofetil (MMF)), and their association with HCV recurrence following liver transplantation.

\section{Subjects and Methods}

2.1. Subjects. Fifty adult patients who underwent LDLT because of $\mathrm{HCV}$ induced end stage liver disease were enrolled and followed up in El Sahel Teaching Hospital. All the procedures were approved by the institution ethical review board according to Helsinki Declaration 1975 revised in 2008. Liver biopsies were taken at six and 12 months. Exclusion criteria include (coinfection with HBV, CMV or HIV, autoimmune hepatitis, alcoholic hepatitis, primary biliary cirrhosis, primary sclerosing cholangitis, fulminant hepatitis, and cryptogenic liver cirrhosis). Demographic data on recruited patients include detailed history, clinical examination, abdominal ultrasonography, liver biopsy, or fibroscan and laboratory testing including hematological and biochemical analyses. Evidence of HCV recurrence post liver transplantation depends on postoperative elevation of liver enzymes, hepatitis $\mathrm{C}$ viral replication demonstrated by polymerase chain reaction, and liver biopsy (histopathological diagnosis includes the presence of hepatitis activity index (HAI) score $\geq 6$ and/or fibrosis staging $\geq 2$ according to the Ishak modification of the Knodell classification). These are assisted six months after liver transplantation.

2.2. Blood Samples. Peripheral blood was withdrawn on EDTA. Genomic DNA was extracted using genomic DNA extraction kits (Qiagen, Milan, Italy). Sera were separated from coagulated blood for testing antischistosomiasis and autoimmune (ANA, AMA, and LKA) Abs. Hematological and biochemical tests (CBC, liver, and kidney functions) were analyzed for all subjects before and after transplantation. Since CMV reactivation was recently shown by our laboratory to interfere with several innate immunity pathways and subsequently poor rates of drug induced HCV clearance $[17,18]$, the presence of CMV DNA was explored in patients' genomic DNA after transplantation.

2.3. Detection of Exon 7 SAS Polymorphism of OAS 1 Gene. Genotyping for exon 7 splicing acceptor site (SAS) of OAS 1 gene (G/A) polymorphism was performed by a PCRRFLP assay. A 203 bp PCR fragment was obtained following a protocol containing SAS specific primers as previously described [14]. Amplified product was digested with AluI (New England Biolabs, Hitchin, UK) and fragments were resolved by electrophoresis on $4 \%$ agarose gel containing ethidium bromide as described [14]. A band of $203 \mathrm{bp}$ indicates the GG genotype, while bands of $150 \mathrm{bp}+53 \mathrm{bp}$ indicate the AA genotype. The heterozygous genotype AG produces 3 bands of $203 \mathrm{bp}+150 \mathrm{bp}+53 \mathrm{bp}$.

2.4. Genotyping of $I L-1 \beta+3953 S N P$. The region spanning the tested SNP was amplified by PCR using sequence specific primers; forward primer: $5^{\prime}$ GTTGTCATCAGACTTTGACC- $3^{\prime}$ and reverse primer: $5^{\prime}$-TTCAGTTCATATGGACCAGA-3' . Reaction mix $(50 \mu \mathrm{L})$ contained 2 units Taq polymerase (Finnzyme, Finland), $5 \mu \mathrm{L}$ of 10X PCR buffer (supplied with the enzyme), $0.2 \mathrm{mM}$ dNTPs (Promega, Madison WI, USA), $1.5 \mathrm{mM} \mathrm{MgCl}_{2}, 5 \mu \mathrm{M}$ from each primer, and $3 \mu \mathrm{L}$ of DNA and DDW to $50 \mu \mathrm{L}$. Thermal cycling protocol comprised initial denaturation at $96^{\circ} \mathrm{C}$ for 5 minutes, followed by 3 cycles each includes $96^{\circ} \mathrm{C}$ for 90 seconds, $53^{\circ} \mathrm{C}$ for 90 , seconds and $72^{\circ} \mathrm{C}$ for 90 seconds, followed by 35 cycles each includes $96^{\circ} \mathrm{C}$ for 
TABLE 1: Laboratory data of patients undergoing LDLT. Blood samples were withdrawn just before surgery. Sera were separated and analyzed for the above parameters.

\begin{tabular}{lcccc}
\hline & Mean \pm SD & Medium & Minimum & Maximum \\
\hline ALT & $67.5 \pm 64.4$ & 47.5 & 6.0 & 290.0 \\
AST & $63.3 \pm 56.5$ & 44.5 & 7.0 & 206.0 \\
ALP & $210 \pm 172$ & 159.5 & 40.0 & 902.0 \\
GGT & $407 \pm 1270$ & 104.5 & 20.0 & 9048.0 \\
T. Protein & $7.1 \pm 0.8$ & 7.1 & 5.1 & 8.9 \\
Albumin & $4.1 \pm 0.5$ & 4.2 & 2.8 & 5.0 \\
T. Bilirubin & $1.3 \pm 1.0$ & 1.0 & 0.3 & 4.3 \\
D. Bilirubin & $0.5 \pm 0.5$ & 0.3 & 0.1 & 2.3 \\
PT & $13.7 \pm 1.1$ & 13.4 & 12.0 & 17.0 \\
PC & $89.9 \pm 14.5$ & 97.5 & 45.0 & 1.9 \\
INR & $1.1 \pm 0.2$ & 1.0 & 0.9 & 3.0 \\
Creatinin & $1.0 \pm 0.5$ & 1.0 & 0.4 & 6.7 \\
K & $4.4 \pm 0.6$ & 4.4 & 3.5 & 146.0 \\
Na & $138.3 \pm 4.1$ & 138.0 & 128.0 & \\
\hline
\end{tabular}

1 minute, $53^{\circ} \mathrm{C}$ for 1 minute, and $72^{\circ} \mathrm{C}$ for 1 minute and a final extension step at $72^{\circ} \mathrm{C}$ for 10 minutes. Amplified products were digested with 2 units Taq I restriction endonuclease (Amersham Pharmacia-Biotech, St Albans, UK) at $65^{\circ} \mathrm{C}$ for 3 hours. Restricted fragments were resolved on $2 \%$ agarose gel electrophoresis. A band of $249 \mathrm{bp}$ indicates the TT genotype, while bands of $135 \mathrm{bp}+114 \mathrm{bp}$ indicate the CC genotype. The heterozygous genotype CT produces 3 bands of $249 \mathrm{bp}+$ $135 \mathrm{bp}+114 \mathrm{bp}$.

2.5. Detection of IL-28 $\beta$ rs12979860 C/T Polymorphism. Genotyping for the IL-28 $\beta$ rs12979860 C/T polymorphism was performed according to protocol described previously [15]. After BstU-I digestion the restricted products were resolved on $4 \%$ agarose gel electrophoresis containing ethidium bromide for staining. A band of $139 \mathrm{bp}$ indicates the T/T genotype, two bands of $109 \mathrm{bp}+30 \mathrm{bp}$ indicate the $\mathrm{C} / \mathrm{C}$ genotype, and 3 bands of $139 \mathrm{bp}+109 \mathrm{bp}+30 \mathrm{bp}$ (invisible) indicate the $\mathrm{C} / \mathrm{T}$ heterozygous.

2.6. Statistical Analysis. The one-year disease-free survival (DFS) rates were correlated with various prognostic factors using Student $t$-test. All the prognostic factors that showed statistical significance $<0.05$ were introduced into Cox proportional hazards model for disease-free survival computation.

\section{Results}

3.1. Clinical and Laboratory Findings of Patients Undergoing LDLT. The clinical data showed that $39(78 \%)$ of patients were males, while $11(22 \%)$ were females, with mean age of $49.9 \pm 8.2$ ranging between 17 and 60 years. The MELD score of the 50 patients before transplant ranged between 12 and 27 with a median of 18 , while the BMI of patients ranged from 20 to 34 with median of 28 . All the studied
TABLE 2: Correlation between DFS and donor's age and liver steatosis. Patients undergoing LDLT were divided into 2 groups according to age (below and above $25 \mathrm{y}$ ) and according to degree of liver steatosis (below and above 3\%). DFS rates were calculated during the first 6 months after surgery and correlated with age and steatosis groups.

\begin{tabular}{lcccc}
\hline & No. of cases & $\begin{array}{c}12 \mathrm{~m} \text { DFS } \\
(\%)\end{array}$ & $P$ value & Sig. \\
\hline All & 50 & 20.6 & & \\
Age & & & & \\
$\quad<25$ & 20 & 36.5 & 0.235 & NS \\
$\quad>25$ & 30 & 21.5 & & \\
Steatosis (\%) & & & & \\
$\quad<3$ & 27 & 51.6 & 0.059 & NS \\
$\quad>3$ & 23 & 0.0 & & \\
\hline
\end{tabular}

patients were Child C. The Child-Pugh score is used to assess the prognosis of chronic liver disease; mainly, cirrhosis and chronic liver disease are classified into Child-Pugh class A to C. Child-Pugh is now used to determine the prognosis, as well as the required strength of treatment and the necessity of liver transplantation. The laboratory data showed that all subjects were HCV RNA positive and negative for HBV, $26 \%$ of patients had HCC, and $54 \%$ had been exposed to schistosoma infection. The biochemical tests of all recipients are summarized in Table 1.

3.2. The Effect of Donor's Age and Liver Steatosis on HCV Recurrence. The donor age ranged from 21 to 40 years with the mean of $27.9 \pm 9.2$ years. Steatosis in the donor's liver ranged from $0 \%$ to $15 \%$ with a median of $3 \%$. When comparing the donor's age and liver steatosis with the DFS we found that the donor's age $(P=0.235)$ and liver steatosis $(P=$ 0.059 ) were nonsignificant factors affecting the postoperative disease-free survival as shown in Table 2. 
TABLE 3: Correlation between DFS and recipient's sex, age, BMI, MELD score, and HCC. Host parameters including sex ratio, age of participants, and BMI and MELD score were determined and were statistically analyzed. The results showed that all host parameters were nonsignificant factors affecting the post operative disease-free survival $(P$ value $=0.776,0.064,0.466$, and 0.663 , resp. $)$.

\begin{tabular}{ccccc}
\hline & No. of cases & $\begin{array}{c}12 \mathrm{~m} \text { DFS } \\
(\%)\end{array}$ & $P$ value & Sig. \\
\hline $\begin{array}{l}\text { All } \\
\text { Sex }\end{array}$ & 50 & 20.6 & & \\
$\quad$ Females & 11 & 0.0 & 0.776 & NS \\
$\quad$ Males & 39 & 25.9 & & \\
Age & & & & \\
$\quad<50$ & 23 & 31.4 & 0.064 & NS \\
$\quad>50$ & 27 & 27.2 & & \\
BMI & & & & \\
$\quad<25$ & 7 & 50.0 & 0.466 & NS \\
$\quad>25$ & 43 & 21.3 & & \\
Meld score & & & & \\
$\quad<18$ & 30 & 23.3 & 0.663 & NS \\
$\quad>18$ & 20 & 43.5 & & \\
HCC & & & & \\
+ & 13 & 33.8 & 0.172 & NS \\
$\quad-$ & 37 & 23.1 & &
\end{tabular}

3.3. The Effect of Recipient's Sex, Age, and BMI and MELD Score on HCV Recurrence. To study the role of the recipient's sex, age, BMI, MELD score, and presence of HCC on the DFS, all parameters were statistically compared with DFS rate. The results showed that $78 \%$ of recipient patients were males, while $22 \%$ were females, with a mean age of $(49.9 \pm 8.2)$ ranging between 17 and 60 years. The BMI of patients ranged from 20 to 34 with median of 28 . The lowest MELD score of the 50 patients before transplantation was 12 and the highest was 27 with a median of 18 while all the studied patients were Child-Pugh C class. The correlation between DFS and recipient's sex, age, and BMI and MELD score is summarized in Table 3.

\subsection{Correlation between Postoperative Laboratory Data and} $\mathrm{HCV}$ Recurrence. Hematological and biochemical analyses including $\mathrm{CBC}$, liver functions, kidney functions, alpha fetoprotein were tested for all subjects at the 6th and 12th month post-transplantation. Also, during the follow-up period samples were taken every six months. The relation of these tests with the postoperative DFS is summarized in Table 4. Postoperative ALT, AST, ALP, albumin, and total serum protein levels showed statistically significant changes with postoperative DFS rates, whereas other hematological and biochemical parameters had not significant correlation with DFS rates. The results shown in Table 4 indicated that only hepatic enzymes and liver specific proteins had statistical correlation with tendency of HCV recurrence. Changes in the remaining parameters seem to be not significantly correlated
TABLE 4: Correlation of postoperative hematological and biochemical parameters with DFS. Several key biochemical and hematological parameters were assayed at the 6th month after LDLT surgery and were correlated with the computed DFS rates that reflect HCV recurrence.

\begin{tabular}{|c|c|c|c|c|}
\hline & No. of cases & $\begin{array}{c}12 \mathrm{~m} \text { DFS } \\
(\%)\end{array}$ & $P$ value & Sig. \\
\hline All & 50 & 20.6 & & \\
\hline \multicolumn{5}{|l|}{$\mathrm{Hb}}$. \\
\hline$<11$ & 11 & 85.7 & \multirow{2}{*}{0.136} & \multirow{2}{*}{ NS } \\
\hline$>11$ & 39 & 0.0 & & \\
\hline \multicolumn{5}{|l|}{ WBCs } \\
\hline$<4000$ & 9 & 25.0 & \multirow{2}{*}{0.052} & \multirow{2}{*}{ NS } \\
\hline 4000-11000 & 21 & 23.9 & & \\
\hline \multicolumn{5}{|l|}{ Platelets } \\
\hline$<150000$ & 20 & 23.7 & \multirow{2}{*}{0.663} & \multirow{2}{*}{ NS } \\
\hline$>150000$ & 30 & 30.8 & & \\
\hline \multicolumn{5}{|l|}{ ALT } \\
\hline$<37$ & 28 & 78.1 & \multirow{2}{*}{$<0.001$} & \multirow{2}{*}{ HS } \\
\hline$>37$ & 22 & 0.0 & & \\
\hline \multicolumn{5}{|l|}{ AST } \\
\hline$<41$ & 26 & 100.0 & \multirow{2}{*}{$<0.001$} & \multirow{2}{*}{ HS } \\
\hline$>41$ & 24 & 0.0 & & \\
\hline \multicolumn{5}{|l|}{ ALP } \\
\hline$<160$ & 26 & 34.9 & \multirow{2}{*}{0.006} & \multirow{2}{*}{ HS } \\
\hline$>160$ & 24 & 0.0 & & \\
\hline \multicolumn{5}{|l|}{ GGT } \\
\hline$<105$ & 25 & 53.9 & \multirow{2}{*}{0.915} & \multirow{2}{*}{ NS } \\
\hline$>105$ & 25 & 19.2 & & \\
\hline \multicolumn{5}{|l|}{ T. proteins } \\
\hline$<7$ & 25 & 12.7 & \multirow{2}{*}{0.027} & \multirow{2}{*}{$S$} \\
\hline$>7$ & 25 & 74.2 & & \\
\hline \multicolumn{5}{|l|}{ Albumin } \\
\hline$<4$ & 17 & 9.8 & 0.017 & $S$ \\
\hline$>4$ & 33 & 71.8 & 0.017 & 0 \\
\hline T. bilirubin & & & & \\
\hline$<1.0$ & 35 & 0.0 & 0.709 & NS \\
\hline$>1.0$ & 15 & 36.6 & 0.109 & NS \\
\hline D. bilirubin & & & & \\
\hline$<0.3$ & 30 & 58.8 & 0.179 & NS \\
\hline$>0.3$ & 19 & 15.9 & 0.179 & No \\
\hline PT & & & & \\
\hline$<13.5$ & 25 & 0.0 & 0.615 & NS \\
\hline$>13.5$ & 25 & 27.5 & 0.615 & No \\
\hline $\mathrm{PC}$ & & & & \\
\hline$<97.5$ & 25 & 19.9 & 0.869 & NS \\
\hline$>97.5$ & 25 & 46.7 & & \\
\hline INR & & & & \\
\hline$<1$ & 26 & 0.0 & 0.587 & NS \\
\hline$>1$ & 24 & 26.5 & & \\
\hline
\end{tabular}


TABLE 4: Continued.

\begin{tabular}{lcccc}
\hline & No. of cases & $\begin{array}{c}12 \mathrm{~m} \text { DFS } \\
(\%)\end{array}$ & $P$ value & Sig. \\
\hline $\begin{array}{l}\text { Urea } \\
\quad 25\end{array}$ & 25 & 23.9 & 0.522 & NS \\
$\quad>25$ & 25 & 0.0 & & \\
$\quad \begin{array}{l}\text { Creatinine } \\
\quad<1.2\end{array}$ & 45 & 39.7 & 0.596 & NS \\
$\quad>1.2$ & 5 & 0.0 & & \\
$\begin{array}{l}\alpha \text { fetoprotein } \\
\quad<3.3\end{array}$ & 25 & 0.0 & & \\
$\quad>3.3$ & 25 & 47.9 & 0.942 & NS \\
\hline
\end{tabular}

NS: nonsignificant statistical correlation, S: significant, and HS: highly significant.

with DFS. Moreover, the minimal degree of hepatitis activity (A1) was shown in $75 \%$ of biopsies while (A2) was observed in the rest $25 \%$. As for fibrosis, the majority $43.75 \%$ were (F1) while $31.25 \%$ were (F0) and the least percentage $25 \%$ was (F2). No advanced fibrosis (F3) or cirrhosis (F4) was detected in liver biopsies.

3.5. Association of HCV RNA Level, Bilharzial, and CMV Coinfection with HCV Recurrence. To examine the role of preoperative levels of HCV RNA, as well as earlier coinfection with schistosoma and CMV, DFS rate was correlated independently with each parameter. The results shown in Table 5 revealed that median levels of HCV RNA were $\left(41 \times 10^{3}\right)$ and $\left(62 \times 10^{3}\right)$ IU before and after transplantation, respectively. Both titers were significantly correlated with DFS rates. On the other hand neither preoperative schistosoma IgG titers nor CMV DNA correlated significantly with DFS. The current patient cohort includes 26\% HCC with no apparent statistically significant correlation with DFS.

3.6. The Association of Recipients' Genetic Variants (OAS, IL1 $\beta$, and IL28B Polymorphisms) with HCV Recurrence. To examine whether single nucleotide polymorphisms (SNPs) in some key genes play roles in determining the rate of $\mathrm{HCV}$ recurrence, SNPs of OAS, IL1 $\beta$, and IL28B genes were studied in patients undergoing LDLT and were statistically correlated with rates of HCV recurrence. The results showed that the OAS and IL1 $\beta$ polymorphisms had no significant association with postoperative DFS. On the other hand the C/C genotype IL28B gene (rs12979860) displayed significant correlation with higher rates of postoperative DFS as shown in Table 6.

3.7. The Disease-Free Survival (DFS) in Relation to Immunosuppressive Drugs. The effects of three different immunosuppressive drugs on HCV recurrence were studied. The results shown in Table 7 showed that the use of MMF was significantly associated with higher rates of postoperative
DFS $(P<0.004)$. On the other hand, the use of CS or FK had no significant effects on DFS rates after transplantation.

3.8. Cox Proportional Hazards Model for all Significant Factors. All factors showed significance level at 0.05 or less were entered into Cox proportional hazards model. Results showed that patients with abnormal ALT and high viral load before transplantation were more likely to develop recurrence than those with normal ALT levels and low viral load. As regards IL28B polymorphism, CC type was not associated with HCV recurrence, while patients with CT type and TT type were more likely to develop recurrence as shown in Table 8.

The results depicted in Table 8 denote that patients with abnormal ALT were 8.28 times more likely to develop recurrence than those with normal ALT levels. Elevated viral RNA titers before transplantation were found to be a significant factor as patients with higher viral load before transplantation were 4.22 times more likely to develop recurrence $(P$ value $=$ 0.028). Regarding IL28B polymorphism, CC genotype was clearly protective against $\mathrm{HCV}$ recurrence, while patients with CT genotype were 3.35 times more likely to develop recurrence and patients with TT genotype were 1.36 times more likely to develop recurrence though not statistically significant.

\section{Discussion}

Chronic infection with $\mathrm{HCV}$ is a leading indication for liver transplantation [19]. The poor outcome of HCVpositive recipients has resulted in divergence in the transplant outcomes between HCV-positive recipients and HCVnegative recipients. Improvements in organ preservation, surgical techniques, and postoperative care have dramatically improved the survival of HCV-negative recipients over the last two decades, whereas this has not been the case in $\mathrm{HCV}$-positive recipients for whom outcome has remained unchanged or even worsened over time [20]. There is a great demand for identifying the factors related to severe hepatitis $\mathrm{C}$ recurrence and disease progression. This study was carried out on 50 patients with chronic HCV-related liver disease who underwent living donor liver transplantation. The current results showed that donor's age did not seem to affect the rate of $\mathrm{HCV}$ recurrence since the majority of donors in this study were under 40 years old with a mean age of $27.9 \pm 4.7$ years, thus supporting the findings of Alonso et al., Lake et al., and Rayhill et al. [21-23] showing that donor's age is the primary risk factor for recurrent hepatitis C with increased severity of recurrence at donors' ages $>40$ years. Degree of steatosis in donors' livers did not exceed $15 \%$ consequently avoiding the possibility of having worse outcome when receiving grafts with $>30 \%$ steatosis as reported by Briceño et al. [24]. Regarding recipient's sex, Lai et al. [25] reported that female sex was an independent predictor of advanced recurrent disease and mortality, a finding that could not be supported by our data showing that sex of recipient does not affect the postoperative disease-free survival $(P=0.776)$. Belli et al. [26] reported 
TABLE 5: Correlation of HCV RNA titers, schistosoma IgG, and CMV DNA with DFS. Each of the abovementioned parameters was divided into 2 groups based on the HCV titer whether above or below the calculated median, presence or absence of IgG Ab, or presence or absence of CMV DNA were statistically compared with DFS rate.

\begin{tabular}{|c|c|c|c|c|}
\hline & No. of cases & $\begin{array}{c}12 \mathrm{~m} \text { DFS } \\
(\%)\end{array}$ & $P$ value & Sig. \\
\hline All & 50 & 20.6 & & \\
\hline \multicolumn{5}{|c|}{ HCV PCR Before Transpl. } \\
\hline$<43000$ & 25 & 82.9 & \multirow{2}{*}{0.003} & \multirow{2}{*}{ HS } \\
\hline$>43000$ & 25 & 0.0 & & \\
\hline \multicolumn{5}{|c|}{ HCV PCR Post Transpl. } \\
\hline$<62500$ & 25 & 100.0 & \multirow{2}{*}{$<0.001$} & \multirow{2}{*}{ HS } \\
\hline$>62500$ & 25 & 0.0 & & \\
\hline \multicolumn{5}{|c|}{ Bilharzial Ab } \\
\hline +ve & 27 & 51.6 & \multirow{2}{*}{0.059} & \multirow{2}{*}{ NS } \\
\hline- ve & 23 & 0.0 & & \\
\hline \multicolumn{5}{|c|}{ CMV PCR Post-Transpl. } \\
\hline$-\mathrm{ve}$ & 30 & 0.0 & \multirow{2}{*}{0.801} & \multirow{2}{*}{ NS } \\
\hline +ve & 20 & 22.5 & & \\
\hline
\end{tabular}

TABLE 6: Correlation of single nucleotide polymorphisms in the OAS, IL1B, and IL28B genes with DFS rates. Total genomic DNA was extracted from patients undergoing LDLT and typed for specific SNPs in or around OAS, IL1B, and IL28B genes. The distribution of different variants was statistically correlated with DFS rates after transplantation.

\begin{tabular}{|c|c|c|c|c|}
\hline & No. of cases & $\begin{array}{c}12 \mathrm{~m} \text { DFS } \\
(\%)\end{array}$ & $P$ value & Sig. \\
\hline All & 50 & 20.6 & & \\
\hline \multicolumn{5}{|c|}{ OAS polymorphism } \\
\hline $\mathrm{AA}$ & 5 & 25.0 & \multirow{3}{*}{0.133} & \multirow{3}{*}{ NS } \\
\hline AG & 40 & 51.3 & & \\
\hline GG & 5 & 0.0 & & \\
\hline \multicolumn{5}{|c|}{ IL1B polymorphism } \\
\hline CC & 22 & 0.0 & \multirow{3}{*}{0.425} & \multirow{3}{*}{ NS } \\
\hline CT & 17 & 30.5 & & \\
\hline $\mathrm{TT}$ & 11 & 18.2 & & \\
\hline \multicolumn{5}{|c|}{$\begin{array}{l}\text { IL28B polymorphism } \\
\text { (rs12979860) }\end{array}$} \\
\hline CC & 10 & 62.5 & \multirow{3}{*}{0.025} & \multirow{3}{*}{$\mathbf{S}$} \\
\hline CT & 31 & 0.0 & & \\
\hline $\mathrm{TT}$ & 9 & 0.0 & & \\
\hline
\end{tabular}

a synergistic effect between donors' age and recipients' female sex, which highlights the importance of using younger donors for female recipients. Liver function tests were repeatedly shown to significantly affect posttransplantation recurrence [27, 28]. Specifically, our data showed that elevated ALT, AST, and ALP levels were associated with increased risk of HCV recurrence $(P<0.001,<0.001$ and $<0.006$ resp. $)$ after LDLT. However, changes in serum levels of GGT did not correlate significantly with DFS rates neither in the current study $(P=0.915)$ nor in the results reported by Feurer et al. [27]. The currently observed data on serum bilirubin and INR posttransplantation ( $P=0.709$ and 0.587 resp. $)$ did not reproduce the results of Charlton et al. [28] who showed that bilirubin and INR are predictors of posttransplant mortality and suggested that these 2 variables reflect general debility of the recipient.

Ghabril et al. [29] found that high viral load in addition to high grade of fibrosis and older donor age is predictors of advanced fibrosis. Our results showed that Hepatitis C viral load before and after transplant (3-6 months) is highly significant factors affecting $\mathrm{HCV}$ recurrence after liver transplantation $(P<0.003$ and $P<0.001$ resp.). In this context, the current results support earlier reports of Khettry et al. [30] and Ciccorossi et al. [31] that high viral load pre-LT 
TABLE 7: Correlation of immunosuppressive agents and DFS posttransplantation. The results show that the use of MMF was highly significant factor affecting the postoperative disease-free survival $(P$ value $=0.004)$, while the use of CS and FK was nonsignificant $(P$ value $=0.337$ and 0.231 resp.).

\begin{tabular}{lcccc}
\hline & No. of cases & $\begin{array}{c}12 \mathrm{~m} \text { DFS } \\
(\%)\end{array}$ & $P$ value & Sig. \\
\hline All & 50 & 20.6 & & \\
CS & & 0.0 & 0.337 & NS \\
$\quad$ C.S & $\mathbf{1 5}$ & 21.3 & & \\
$\quad$ None & $\mathbf{3 5}$ & & & \\
FK & & 20.6 & 0.231 & NS \\
$\quad$ F.K & $\mathbf{3 3}$ & 0.0 & & \\
$\quad$ None & $\mathbf{1 7}$ & & & \\
MMF & & 0.0 & 0.004 & HS \\
MMF & $\mathbf{3 2}$ & 66.7 & & \\
None & $\mathbf{1 8}$ & &
\end{tabular}

was correlated with more progressive recurrence of HCV and higher early (1 week) posttransplantation viral loads $(\geq 2.5 \times$ $10^{5} \mathrm{IU} / \mathrm{mL}$ ) are at risk for significant recurrent hepatitis C. These data suggest that patients who are at risk for significant HCV recurrence can be identified early.

Although cytomegalovirus (CMV) infection was thought to be associated with more progressive chronic HCV disease and worse recurrent $\mathrm{HCV}$, possibly via its association with host immunosuppression, the current data showed no association of CMV infection of the recipient with diseasefree survival $(P \leq 0.801)$, thus supporting earlier reports who failed to show a correlation between CMV infection and HCV recurrence [32,33]. Burak et al. [34], on the other hand, reported that graft failure was significantly more common in patients with CMV infection versus those without CMV.

We currently examined the association of $2^{\prime}, 5^{\prime}$-oligoadenylate synthetase (OAS), interleukin $1 \beta(\operatorname{IL} 1 \beta)$, and Interleukin $28 \beta$ (IL28B) polymorphisms with the rate of HCV recurrence following liver transplantation. Results showed that the heterozygous form of OAS A/G was more common than $\mathrm{A} / \mathrm{A}$ and $\mathrm{G} / \mathrm{G}$ with highest rate of 6 months disease-free survival (51.3\% for $A / G$ versus 25.0 and $0.0 \%$ for $A / A$ and $G / G$ resp.) but was statistically nonsignificant $(P \leq 0.133)$. These data were contradictory to those published by Whitehill, [35] who reported that OAS genotype A/G had the highest rate of HCV recurrence post-transplantation within 12 months. Although IL1 $\beta$ has been shown to be a key cytokine in development of steatosis and hence liver fibrosis, the current data showed no significant association of IL1 $\beta$ polymorphism with HCV recurrence after transplantation $(P \leq 0.425)$. To the limit of our knowledge, no published data are available on the association of IL1 $\beta$ SNP with DFS rates after LDLT. However, IL1 $\beta$ SNPs were found to affect the outcome of hematopoietic stem cell transplantation as it was one of gene variants which have been reproducibly associated with graftversus-host disease (GVHD) [36, 37]. In contrary, genetic variations of IL28B had statistically significant association with the severity of HCV recurrence after LDLT. Recipients with genotypes (CT and TT) had higher risk of severe HCV recurrence than those bearing a CC genotype $(P \leq$ $0.025)$. These results agree well with the previous reports on associations of IL28B SNP with histologic recurrence of HCV posttransplantation $[38,39]$. We can then speculate that genetic variants in IL28B gene might be associated with histological recurrence of HCV and are reproducible predictors of complications during the first year after LT.

A tacrolimus based regimen (with adjusted dose according to patient's trough serum level) is the main immunosuppression protocol used in this study. This regimen is accompanied with steroids that taper gradually till completely withdrawn at the end of the twelfth week. Shift of tacrolimus to cyclosporine occurs in patients who experience tacrolimus related side effects. Recently, Kim et al. [40] compared recipients of LDLT who received cyclosporine and tacrolimus as immunosuppressive agents. Their results indicated that graft and patient survival rates were similar in the 2 groups, but histologic HCV-recurrence-free survival was significantly higher in the cyclosporine group. Also, Irish et al. [41] found that patient and graft survival rates with cyclosporine and tacrolimus were relatively similar. Thus, there was no definitive evidence in favor of one immunosuppressive agent over the other for reducing the risk of recurrent hepatitis $\mathrm{C}$, and selection of immunosuppressive agents should be based on individual patient's data. We also observed that the use of either immunosuppressant had no statistical correlation with DFS rates $(P \leq 0.33$ and $P \leq 0.23$ for $\mathrm{CS}$ and $\mathrm{FK}$ resp.). In this study, the addition of mycophenolate mofetil (MMF) significantly increases HCV recurrence and severity $(P \leq 0.004)$, thus supporting the results of Nelson et al. [42], who reported severe hepatitis $C$ recurrence in patients subjected to induction with MMF when compared with standard therapy based on tacrolimus. Klintmalm et al. [43] reported that the overall intensity of immunosuppression rather than the independent action of either drug may have greater impact on HCV recurrence. On the other hand, Jain et al. [44] compared tacrolimus, mycophenolate mofetil, and prednisone to tacrolimus and prednisone alone and found that there were no differences in graft loss or rate of HCV recurrence. In our attempt to benefit from the designed Cox proportional hazards model we found that patients with abnormal ALT and high viral load before transplantation were 8.28 and 4.22 times, respectively, more likely to develop recurrence while patients with IL28B genotype CT and TT were 3.35 and 1.36 times, respectively, more likely to develop recurrence. In conclusion, assessment of IL28B polymorphism, level of ALT, HCV RNA load before transplantation, and proper choice of immunosuppressant agents are helpful predictors for posttransplantation recurrence and disease severity. Future studies on larger cohorts are required to evaluate potential roles of different genetic polymorphisms and to plan for proper management strategies.

\section{Conflict of Interests}

All authors declare that they have no conflict of interests. 
TABLE 8: Cox proportional hazards model for all significant factors. The most important 3 factors affecting the HCV recurrence after LDLT were subjected to Cox proportional hazards analysis where B is the regression coefficient, SE is the standard error or means, and HR is the hazardous ratio.

\begin{tabular}{|c|c|c|c|c|c|c|}
\hline & \multirow{2}{*}{ B } & \multirow{2}{*}{ SE } & \multirow{2}{*}{$P$-value } & \multirow{2}{*}{ HR } & \multicolumn{2}{|c|}{$95.0 \% \mathrm{CI}$ for $\mathrm{HR}$} \\
\hline & & & & & Lower & Upper \\
\hline Postoperative ALT & 2.125 & 0.648 & 0.001 & 8.28 & 2.35 & 29.82 \\
\hline Preoperative HCV titer & 1.439 & 0.656 & 0.028 & 4.22 & 1.17 & 15.24 \\
\hline \multicolumn{7}{|l|}{ IL28B } \\
\hline $\mathrm{CC}$ & Reference & & 0.223 & & & \\
\hline CT & 1.210 & 0.863 & 0.161 & 3.35 & 0.62 & 18.19 \\
\hline TT & 0.310 & 0.805 & 0.700 & 1.36 & 0.28 & 6.61 \\
\hline
\end{tabular}

$P$ value $<0.05$ is considered significant.

\section{Acknowledgments}

This work was partially funded through the Science and Technology Development Fund (STDF), Egypt, Grant no. 3365 to Dr. Mostafa El Awady.

\section{References}

[1] E. de Martin, K. I. Rodriguez-Castro, A. Vitale et al., "Antiviral treatment for HCV recurrence after liver transplantation: when, how much and for how long?" Future Virology, vol. 6, no. 10, pp. 1179-1186, 2011.

[2] E. J. Gane, B. G. Portmann, N. V. Naoumov et al., "Long-term outcome of hepatitis $\mathrm{C}$ infection after liver transplantation," The New England Journal of Medicine, vol. 334, no. 13, pp. 815-820, 1996.

[3] M. Garcia-Retortillo, X. Forns, A. Feliu et al., "Hepatitis C virus kinetics during and immediately after liver transplantation," Hepatology, vol. 35, no. 3, pp. 680-687, 2002.

[4] B. Roche and D. Samuel, "Risk factors for hepatitis C recurrence after liver transplantation," Journal of Viral Hepatitis, vol. 14, no. 1, pp. 89-96, 2007.

[5] A. J. Demetris, "Evolution of hepatitis C virus in liver allografts," Liver Transplantation, vol. 15, no. 2, pp. S35-S41, 2009.

[6] K. Watt, B. Veldt, and M. Charlton, "A practical guide to the management of hcv infection following liver transplantation," American Journal of Transplantation, vol. 9, no. 8, pp. 1707-1713, 2009.

[7] C. Frank, M. K. Mohamed, G. T. Strickland et al., "The role of parenteral antischistosomal therapy in the spread of hepatitis C virus in Egypt," The Lancet, vol. 355, no. 9207, pp. 887-891, 2000.

[8] A. Elkady, Y. Tanaka, F. Kurbanov et al., "Genetic variability of hepatitis C virus in south Egypt and its possible clinical implication," Journal of Medical Virology, vol. 81, no. 6, pp. 10151023, 2009.

[9] I. Mostafa, M. Abd el Aal, and M. Syam, "HCV recurrence in adult living related transplantation: initial results of starting population," Liver Transplantation, vol. 11, pp. 456-462, 2005.

[10] A. Yosry, M. Abdel-Rahman, G. Esmat et al., "Recurrence of hepatitis $\mathrm{C}$ virus (genotype 4) infection after living-donor liver transplant in Egyptian patients," Experimental and Clinical Transplantation, vol. 7, no. 3, pp. 157-163, 2009.

[11] S. Ciesek and H. Wedemeyer, "Immunosuppression, liver injury and post-transplant HCV recurrence," Journal of Viral Hepatitis, vol. 19, no. 1, pp. 1-8, 2012.
[12] M. Berenguer, "Host and donor risk factors before and after liver transplantation that impact HCV recurrence," Liver Transplantation, vol. 9, no. 11, pp. S44-S47, 2003.

[13] T. Poynard, P. Bedossa, and P. Opolon, "Natural history of liver fibrosis progression in patients with chronic hepatitis C," The Lancet, vol. 349, no. 9055, pp. 825-832, 1997.

[14] M. K. El Awady, M. A. Anany, G. Esmat et al., "Single nucleotide polymorphism at exon 7 splice acceptor site of OAS1 gene determines response of hepatitis $\mathrm{C}$ virus patients to interferon therapy," Journal of Gastroenterology and Hepatology, vol. 26, no. 5, pp. 843-850, 2011.

[15] M. K. El Awady, L. Mostafa, A. A. Tabll, T. H. Abdelhafez, N. G. Bader El Din, and N. Zayed, "Association of IL28B SNP with progression of Egyptian HCV genotype 4 patients to end stage liver disease," Hepatitis Monthly, vol. 12, no. 4, pp. 271-277, 2012.

[16] E. Cisneros, I. Baños, M. J. Citores et al., "Increased risk of severe hepatitis $\mathrm{C}$ virus recurrence after liver transplantation in patients with a T allele of IL28B rs12979860," Transplantation, vol. 94, no. 3, pp. 275-280, 2012.

[17] N. G. Bader El Din, M. Abd El Meguid, A. A. Tabll et al., "Human cytomegalovirus infection inhibits response of chronic hepatitis-C-virus-infected patients to interferon-based therapy," Journal of Gastroenterology and Hepatology, vol. 26, no. 1, pp. 55-62, 2011.

[18] A. Tabll, S. Shoman, H. Ghanem, M. Nabil, N. G. B. El Din, and M. K. El Awady, "Assessment of human cytomegalovirus coinfection in Egyptian chronic HCV patients," Virology Journal, vol. 8, article 343, 2011.

[19] B. Dominuez-Gil and J. M. Morales, "Transplantation in the patients with hepatitis C," Transplant International, pp. 11171131, 2009.

[20] P. J. Thuluvath, K. L. Krok, D. L. Segev, and H. Y. Yoo, “Trends in post-liver transplant survival in patients with hepatitis C between 1991 and 2001 in the United States," Liver Transplantation, vol. 13, no. 5, pp. 719-724, 2007.

[21] O. Alonso, C. Loinaz, E. Moreno et al., "Advanced donor age increases the risk of severe recurrent hepatitis $\mathrm{C}$ after liver transplantation," Transplant International, vol. 18, no. 8, pp. 902-907, 2005.

[22] J. R. Lake, J. S. Shorr, B. J. Steffen, A. H. Chu, R. D. Gordon, and R. H. Wiesner, "Differential effects of donor age in liver transplant recipients infected with hepatitis $B$, hepatitis $C$ and without viral hepatitis," American Journal of Transplantation, vol. 5, no. 3, pp. 549-557, 2005.

[23] S. C. Rayhill, Y. M. Wu, D. A. Katz et al., "Older donor livers show early severe histological activity, fibrosis, and graft failure 
after liver transplantation for hepatitis C,' Transplantation, vol. 84, no. 3, pp. 331-339, 2007.

[24] J. Briceño, R. Ciria, M. Pleguezuelo et al., "Impact of donor graft steatosis on overall outcome and viral recurrence after liver transplantation for hepatitis C virus cirrhosis," Liver Transplantation, vol. 15, no. 1, pp. 37-48, 2009.

[25] J. C. Lai, E. C. Verna, R. S. Brown et al., "Hepatitis c virusinfected women have a higher risk of advanced fibrosis and graft loss after liver transplantation than men," Hepatology, vol. 54, no. 2, pp. 418-424, 2011.

[26] L. S. Belli, A. K. Burroughs, P. Burra et al., "Liver transplantation for HCV cirrhosis: improved survival in recent years and increased severity of recurrent disease in female recipients: results of a long term retrospective study," Liver Transplantation, vol. 13, no. 5, pp. 733-740, 2007.

[27] I. D. Feurer, J. K. Wright, J. L. Payne et al., "Effects of hepatitis $\mathrm{C}$ virus infection and its recurrence after liver transplantation on functional performance and health-related quality of life," Journal of Gastrointestinal Surgery, vol. 6, no. 1, pp. 108-115, 2002.

[28] M. Charlton, K. Ruppert, S. H. Belle et al., "Long-term results and modeling to predict outcomes in recipients with $\mathrm{HCV}$ infection: results of the NIDDK liver transplantation database," Liver Transplantation, vol. 10, no. 9, pp. 1120-1130, 2004.

[29] M. Ghabril, R. C. Dickson, M. Krishna et al., "Explanted liver inflammatory grade predicts fibrosis progression in hepatitis $\mathrm{C}$ recurrence," Liver Transplantation, vol. 17, no. 6, pp. 685-694, 2011.

[30] U. Khettry, W.-Y. Huang, M. A. Simpson et al., "Patterns of recurrent hepatitis $\mathrm{C}$ after liver transplantation in a recent cohort of patients," Human Pathology, vol. 38, no. 3, pp. 443452, 2007.

[31] P. Ciccorossi, A. M. Maina, F. Oliveri et al., "Viral load 1 week after liver transplantation, donor age and rejections correlate with the outcome of recurrent hepatitis C," Liver International, vol. 27, no. 5, pp. 612-619, 2007.

[32] R. Teixeira, S. Pastacaldi, S. Davies et al., "The influence of cytomegalovirus viraemia on the outcome of recurrent hepatitis C after liver transplantation," Transplantation, vol. 70, no. 10, pp. 1454-1458, 2000.

[33] A. Humara, D. Kumar, J. Raboud et al., "Interactions between cytomegalovirus, human herpesvirus-6, and the recurrence of hepatitis C after liver transplantation," American Journal of Transplantation, vol. 2, no. 5, pp. 461-466, 2002.

[34] K. W. Burak, W. K. Kremers, K. P. Batts et al., "Impact of cytomegalovirus infection, year of transplantation, and donor age on outcomes after liver transplantation for hepatitis C," Liver Transplantation, vol. 8, no. 4, pp. 362-369, 2002.

[35] D. Whitehill, "Treatment of type 2 diabetes mellitus and the incretin system," South Dakota Medicine, vol. 60, no. 5, pp. 197199, 2007.

[36] H. Cullup, A. M. Dickinson, J. Cavet, G. H. Jackson, and P. G. Middleton, "Polymorphisms of interleukin- $1 \alpha$ constitute independent risk factors for chronic graft-versus-host disease after allogeneic bone marrow transplantation," British Journal of Haematology, vol. 122, no. 5, pp. 778-787, 2003.

[37] M. L. MacMillan, G. A. Radloff, T. E. DeFor, D. J. Weisdorf, and S. M. Davies, "Interleukin-1 genotype and outcome of unrelated donor bone marrow transplantation," British Journal of Haematology, vol. 121, no. 4, pp. 597-604, 2003.
[38] D. Eurich, S. Boas-Knoop, M. Ruehl et al., "Relationship between the interleukin-28b gene polymorphism and the histological severity of hepatitis $C$ virus-induced graft inflammation and the response to antiviral therapy after liver transplantation," Liver Transplantation, vol. 17, no. 3, pp. 289-298, 2011.

[39] M. R. Charlton, A. Thompson, B. J. Veldt et al., "Interleukin-28B polymorphisms are associated with histological recurrence and treatment response following liver transplantation in patients with hepatitis C virus infection," Hepatology, vol. 53, no. 1, pp. 317-324, 2011.

[40] R. D. Kim, S. Mizuno, J. B. Sorensen, J. J. Schwartz, and S. Fujita, "Impact of calcineurin inhibitors on hepatitis $\mathrm{C}$ recurrence after liver transplantation," Digestive Diseases and Sciences, vol. 57, no. 2, pp. 568-572, 2012.

[41] W. D. Irish, S. Arcona, D. Bowers, and J. F. Trotter, "Cyclosporine versus tacrolimus treated liver transplant recipients with chronic hepatitis C: outcomes analysis of the UNOS/OPTN database," American Journal of Transplantation, vol. 11, no. 8, pp. 1676-1685, 2011.

[42] D. R. Nelson, C. Soldevila-Pico, A. Reed et al., "Antiinterleukin-2 receptor therapy in combination with mycophenolate mofetil is associated with more severe hepatitis C recurrence after liver transplantation," Liver Transplantation, vol. 7, no. 12, pp. 1064-1070, 2001.

[43] G. B. Klintmalm, G. L. Davis, L. Teperman et al., "A randomized, multicenter study comparing steroid-free immunosuppression and standard immunosuppression for liver transplant recipients with chronic hepatitis C," Liver Transplantation, vol. 17, no. 12, pp. 1394-1403, 2011.

[44] A. Jain, R. Kashyap, A. J. Demetris, B. Eghstesad, R. Pokharna, and J. J. Fung, "A prospective randomized trial of mycophenolate mofetil in liver transplant recipients with hepatitis C," Liver Transplantation, vol. 8, no. 1, pp. 40-46, 2002. 


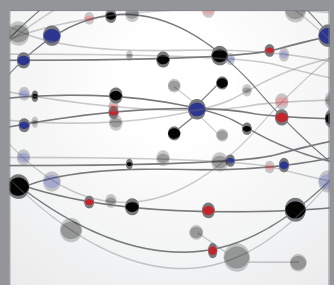

The Scientific World Journal
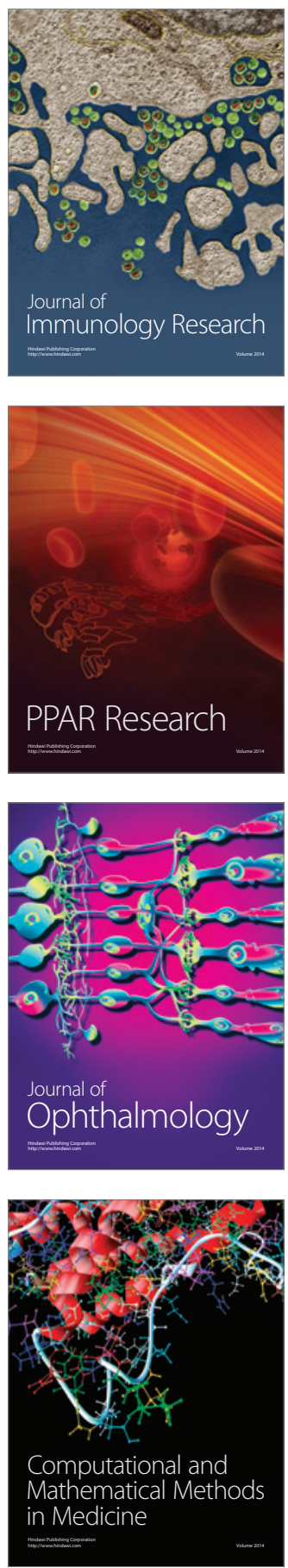

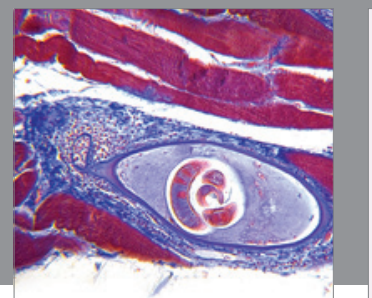

Gastroenterology

Research and Practice
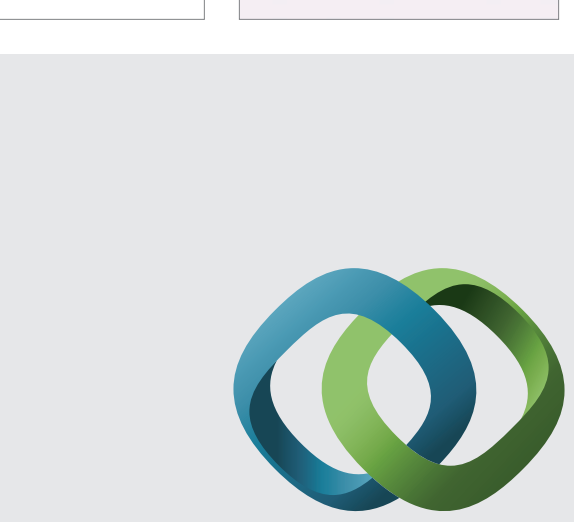

\section{Hindawi}

Submit your manuscripts at

http://www.hindawi.com
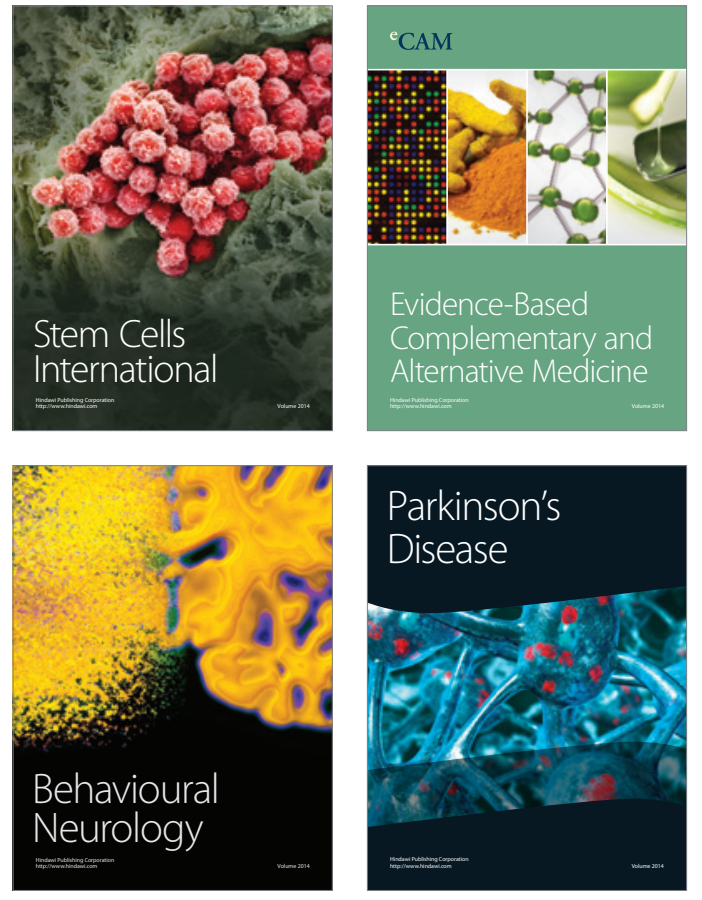
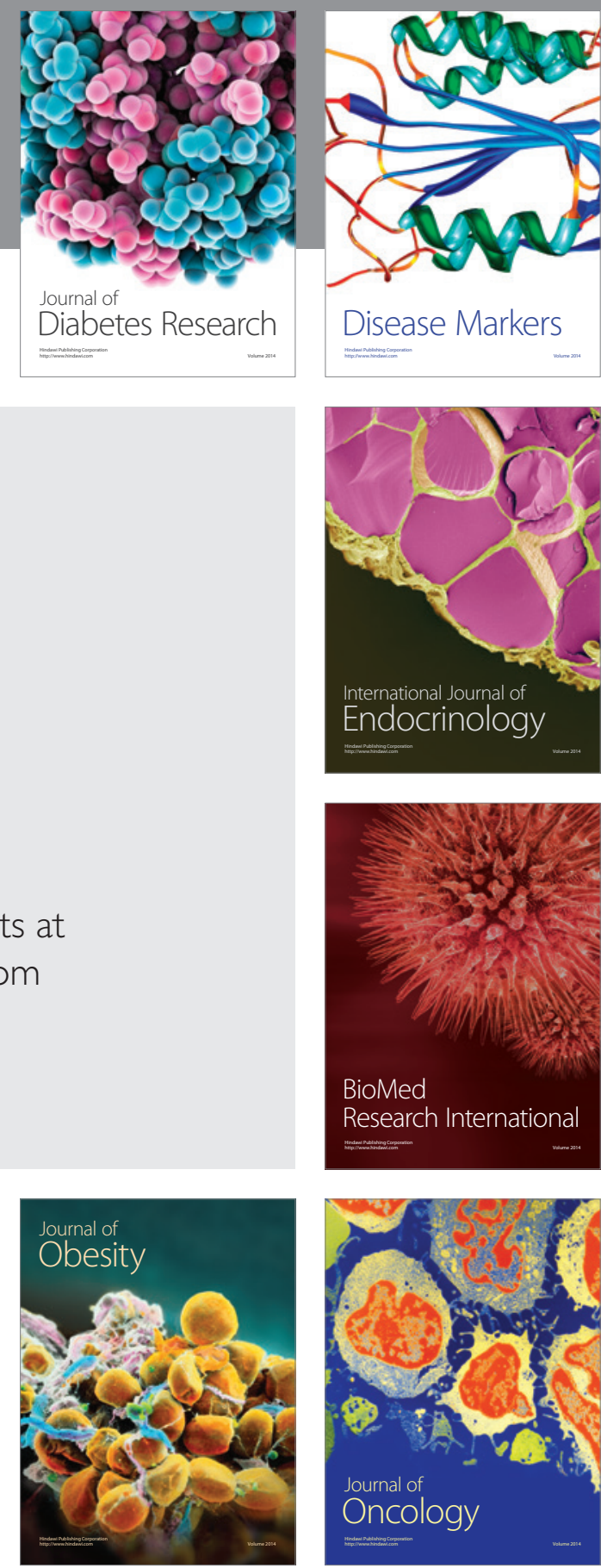

Disease Markers
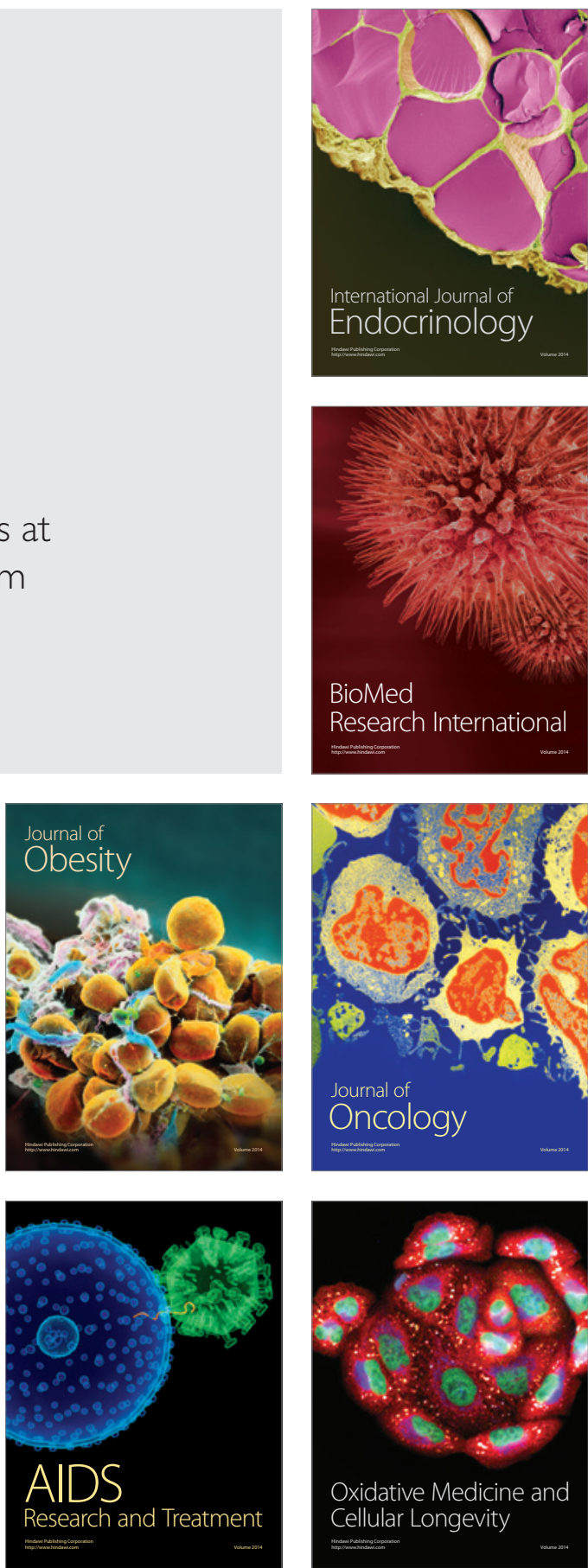